\title{
Local Versus Full Width Pavement Rehabilitation in the Frame of Old Water Supply Network Repair
}

\author{
Grigorios Papageorgiou, Christos Zografos, Nikolaos Alamanis, Nikolaos Xafoulis, Evangelia \\ Farsirotou
}

\begin{abstract}
Since the global financial crisis of 2008, all construction related activities are now subject to cost control of each project. An important component of the optimal choice is the implementation cost. The evaluation of construction activities can be conducted by estimating their environmental as well as their cost footprint, which is also the demand and consumption measure for the societies' needs. Water and sewerage projects have a key role in the standard of living, Public Health and environment. Therefore, water supply network replacements are important to upgrade the quality and quantity of water, through cost-effective choices. The purpose of this study is to present and comment on the uniform cost footprint through the complete replacement of the old water supply network along with complete reconstruction of pavement compared to local repair activities. Usual practices in repair works of old networks and flexible pavement rehabilitations are presented, assessing the benefits of total reconstruction by carrying out life cycle cost analysis in terms of uniform cost per year. The project of replacing the water supply network in the municipality of Larissa, Greece for the period 2015-2019 is analyzed, linking water savings with simultaneous total pavement rehabilitation, calculating average cost per inhabitant and hydrometer, comparing cost and pavement surface area between total and localized rehabilitation activities for a twenty-year rollback period. The fruitful findings of this research study, indicate that full-width pavement rehabilitation along with new water supply network establishment is economically advantageous compared to local rehabilitation treatments, according to the time period considered. Thus, competent authorities can use the proposed methodology as a useful tool to conclude to the optimal choice for maintaining water supply networks in a cost-effective way.

Keywords: cost footprint, local repair environmental footprint, pavement reconstruction, water supply network.
\end{abstract}

\section{INTRODUCTION}

Cost ost footprint of urban infrastructure management is linked to climate change and sustainable development, issues that are the world's most important challenges for planet Earth.

Revised Manuscript Received on February 05, 2020.

* Correspondence Author

Grigorios Papageorgiou, Assistant Professor, University of Thessaly, Larissa, Greece.

Christos Zografos, M.Sc. Degree in Infrastructure Engineering, Dept. of Civil Engineering T.E., Technological Educational Institute of Thessaly.

Nikolaos Alamanis, M.Sc. Degree in Infrastructure Engineering, Dept. of Civil Engineering T.E., Technological Educational Institute of Thessaly.

Nikolaos Xafoulis, M.Sc. Degree in Infrastructure Engineering, Dept. of Civil Engineering T.E., Technological Educational Institute of Thessaly.

Evangelia Farsirotou, Professor , Department of Ichthyology \& Aquatic Environment, School of Agricultural Sciences, laboratory of "Ecohydraulics \& Inland Water Management" at the University of Thessaly

(c) The Authors. Published by Blue Eyes Intelligence Engineering and Sciences Publication (BEIESP). This is an open access article under the CC BY-NC-ND license (http://creativecommons.org/licenses/by-nc-nd/4.0/)

Since 2008, the impact of human activities on the environment has been systematically assessed. Analysis of the annual data collected indicates that most of the carbon

As for the environmental footprint of asphalt, storing, dioxide emissions observed in the activities comes from the production, transportation, application and recycling of products produced. commerce and processing conventional and modified asphalt products requires attention and responsibility that becomes even more demanding once we choose to follow an environmentally friendly path. In order to reduce the impact of our activities on the environment, a number of parameters are taken into account, the most important of which are energy requirements to maintain high temperatures at all stages of the commercial / production process, the efficient management of air pollutant emissions, liquid and solid waste, as well as noise level and leakage control. The water footprint of national consumption is calculated as the total use of domestic water resources plus virtual water import minus virtual water extraction. The water used in the production process of an agricultural or industrial product is called the "virtual water" [1]. The water footprint of the global average consumer in the period 1996-2005 was 1,385 m³/yr [2]. Emphasized that there are differences between countries. The average consumer in the US has a water footprint of $2,842 \mathrm{~m}^{3} / \mathrm{yr}$, while the average citizens in China [12] and India [13] have water footprints of $1,071 \mathrm{~m}^{3} / \mathrm{yr}$ and $1,089 \mathrm{~m}^{3} / \mathrm{yr}$, respectively. The purpose of this work is to present water pipes network replacement along with full-width pavement rehabilitation in the Municipality of Larissa during the 2015-2019 period, which minimised water loss of the old network while improving the quality of the water consumed by the population of the city. While usual practice is focused on localized treatments leading to significant repair costs [14], the present study proposes a comparison of full-scale rehabilitation opposed to local repair activities, in order to conclude to the optimal option.

\section{PROPOSED METHODOLOGY}

\section{A. General}

The types of environmental footprint are land use, carbon and water footprint. The Earth has about 12 million hectares of land divided into forests, pastures, arable areas and fisheries and residential land [3]. Land footprint is the actual amount of land required to produce a product or is used by

an organization or nation and evaluates indigenous and offshore areas that are needed directly or indirectly to satisfy omestic final consumption. 
Due to data limitations, land footprint studies are often focused on agricultural and forest areas [4].

The concept of carbon footprint captures the interest of businesses, consumers and policymakers. It is the sum of greenhouse gas emissions that are directly or indirectly caused by an individual, organization, event or product. The ever-increasing need for water consumption results in significant quantitative and qualitative degradation of water resources. The water footprint is part of the ecological footprint. It is an indicator of water consumption that examines the direct and indirect use of water by the consumer and producer over a period of time [5]. It is calculated, similarly to other types of footprints, for a person, community, process or business. The volume of water consumed is measured in cubic meters $\left(\mathrm{m}^{3}\right)$.

Given the above, this research adopts a life cycle cost analysis in terms of uniform cost per year in order to assess the necessary expenses of full-with pavement rehabilitation along with water supply network replacement opposed to localized repair operations. The project of replacing the water supply network in the municipality of Larissa for the period 2015 - 2019 is analyzed, linking water savings with simultaneous total pavement rehabilitation, calculating average cost per inhabitant and hydrometer, comparing cost and pavement surface area between total and localized rehabilitation activities for a twenty-year rollback period.

\section{B. Replacement and restoration projects}

\section{i. Problems with the old water supply networks}

The problems with the old water supply systems are many and are summarized in the following categories [6]:

- Water losses

- Water quality

- Problematic operation of networks

- Pavement distress

Certainly, old networks are considered inappropriate, both in terms of materials and in terms of water losses from the numerous fractures of asbestos pipes as well as highly corroded iron pipes. A direct consequence of the above is the poor water quality, the defective operation of certain components (e.g. valves), isolation of networks, disruption of water supply and general disruption to more residents [7].

Also, the inadequacy of the old water supply networks results in serious defects of pavement surfaces. Excess water found in the gaps of pores is responsible for many pavement obsolescence incidents [8]. Along with the increase in the amount of water contained in the base and subbase, there is a percentage loss of bearing capacity and, in parallel, an increased loss of pavement serviceability. Since the free water flow fills existing gaps between the layers, vehicle wheel loads on the pavement surface result in water pressure increase.

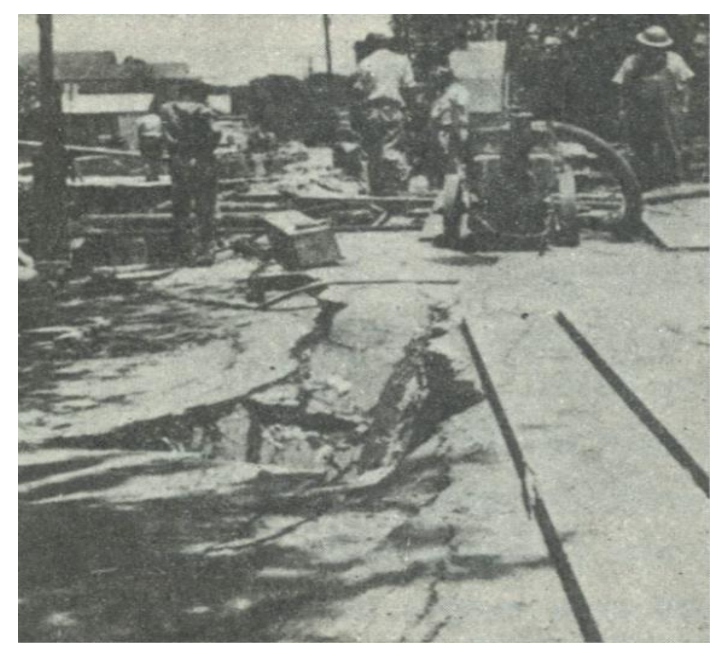

Fig. 1. Pavement subsidence after damage on the old water supply system in the city of Mobile, Alabama, USA [9].

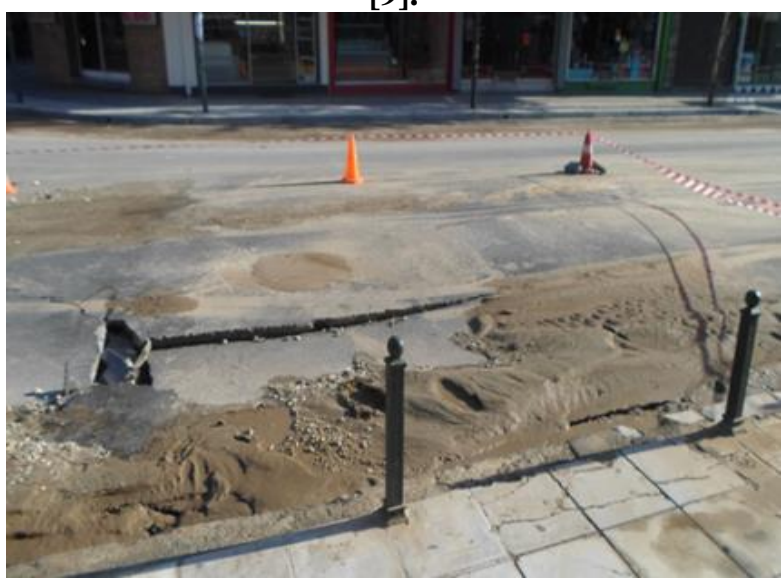

Fig. 2. Pavement destruction due to corrosion of the water pipe, Cyprus Street, Larissa.

Water affects the cement-treated bases as well as the asphalt base layers, causing them to decompose and weaken, resulting in a rearrangement of the internal structure of the fine granules in the aggregate mixtures. Water is responsible for causing excessive stresses in the subsoil. It also contributes to cracking from oxidation and reduces pavement flexibility. In addition to corrosion and removal of material from the pavement, pulsating water pressures also strip asphalt coatings [10]. Consequently, in addition to the danger of traffic due to subsidence (Fig. 1, 2), there is also excessive financial burden on municipalities and their businesses for their restoration.

\section{ii. Network replacement projects - practices}

Cuts containing water supply networks in the urban area are mainly along the old network with the first stage to be cut of the asphalt on both sides of the pavement, in relation to the axis of the new network, and at a width of $0.70 \mathrm{~m}$. Excavation is carried out at a depth of $1.20 \mathrm{~m}$ using mechanical means as well as manually in the event of obstructions by other public utilities. New products such as sand and crushed quarry gravel are used in the cover process. Subsequent work includes the formation of the bottom of the cut, removal of stones that may damage new pipework and placement of quarry sand to a thickness of 10 $\mathrm{cm}$.

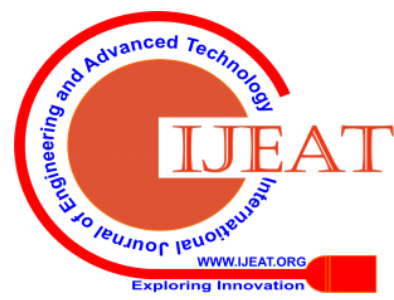


Next, the installation of new polyethylene (PE-16atm) pipes, as well as the new special joint sections, follows (Fig. 3).
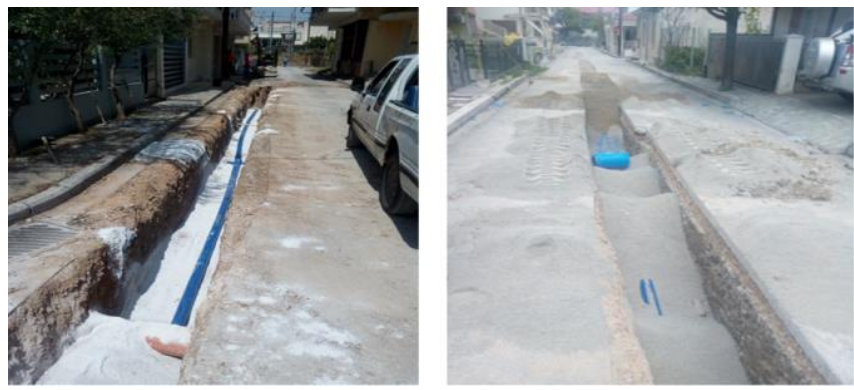

Fig. 3. Installation of new polyethylene water pipe, PE-16atm.

iii. Asphalt segments restoration projects in water supply trenches

Restoration work on a stripped asphalt pavement begins by layering and compacting with inert quarry material in the trench [11]. When the trench filling reaches $5 \mathrm{~cm}$ below the surface of the old asphalt, asphalt pre-treatment is applied and then the base layer asphalt mixture is prepared by heating in a permanent installation, condensed to a thickness of $5 \mathrm{~cm}$. After laying, the asphalt mixture is compacted using a mechanical compactor, vibrating plate or small vibratory roller (Fig. 4).

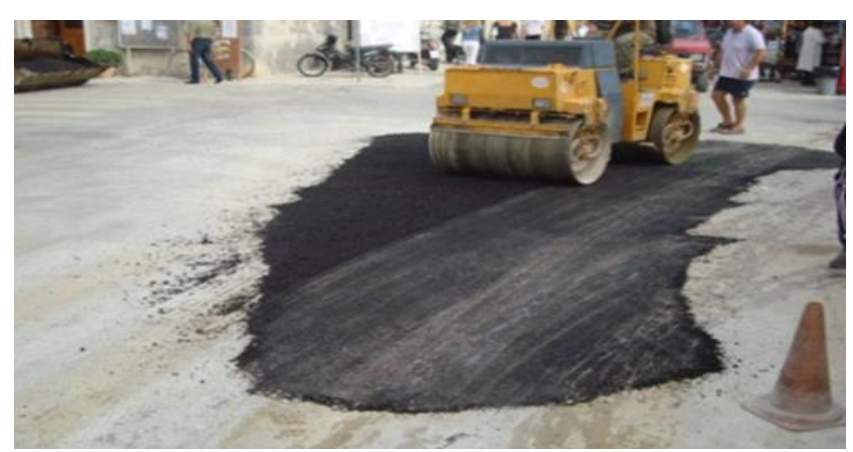

Fig. 4.Compaction of asphalt mix by vibratory roller following water supply network failure.

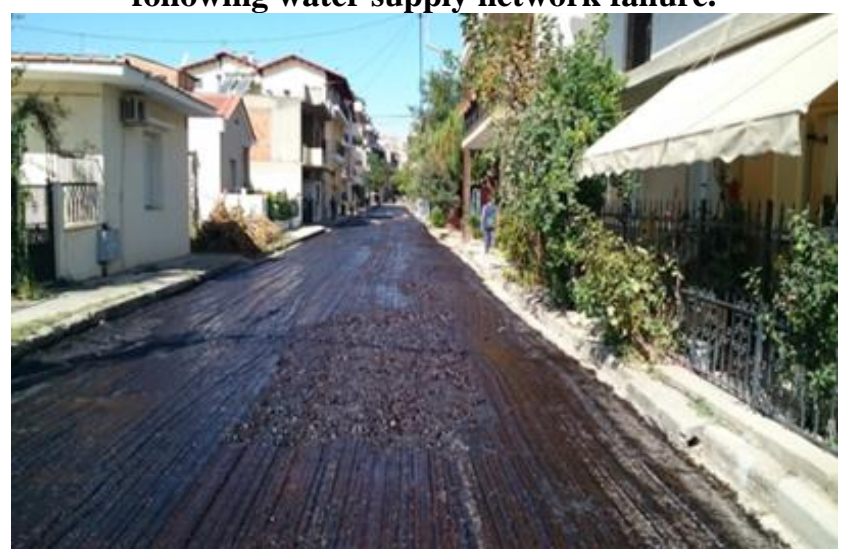

Fig. 5. Pavement adhesive application, district of Agios Georgios, Larissa, Greece.

\section{Steps for implementing proposed methodology}

The steps to implement the proposed methodology are as following:

a) Collection of water supply system historical data.

b) Cost of partial and total asphalt paving

c) Cost of flexible pavement per inhabitant for design time period

d) Paving cost per hydrometer for design time period

e) Total rehabilitated surface in design time period

f) Rehabilitation cost per square meter for design time period

After implementing all the above steps, the findings lead to the optimal choice in terms of the uniform cost values for pavement rehabilitation per year, meaning that the less cost leads to the optimal option.

\section{RESULTS}

\section{A. Water supply in the Municipality of Larissa}

With the aim of water adequacy, savings and accessibility as a social good, the DEYAL has invested 52.6 million $€$, in recent years. During the last five years (2015-2019) in the Municipality of Larissa, old water supply networks (asbestos and iron pipes) were replaced, totalling 120,000 meters, exceeding $60 \%$ of the old networks, with the aim of fully replacing the old networks by 2023 (Fig. 6). In all new projects, except for the network replacements, total asphalting of the pavements has been carried out.

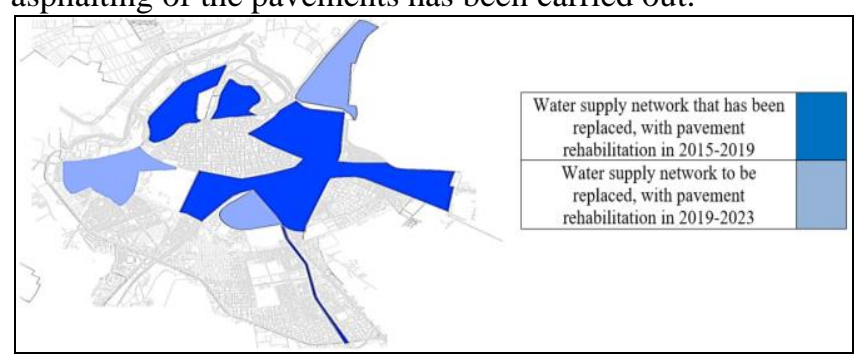

Fig. 6. Water Supply Network Replacement

Map-Memorandum in the Municipality of Larissa, 2015-2023.

The new projects reduced the water supply losses (Fig. 7) due to leaks from $24 \%$ in 2015 to $21 \%$ today. The levels of specific water losses in the municipality of Larissa are among the lowest in Greece considering that in most municipalities in the country the losses reach $50 \%$.

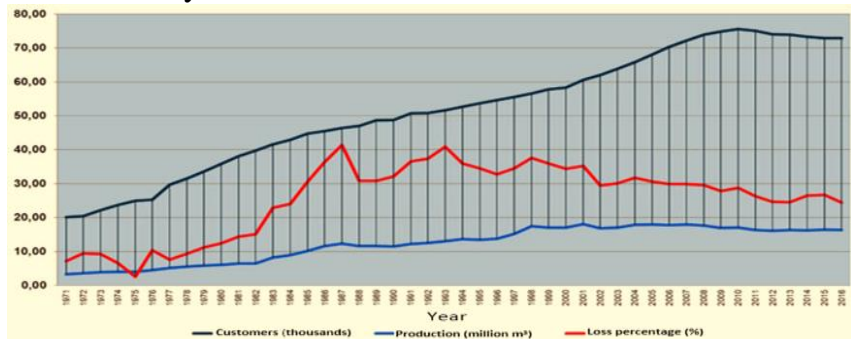

Fig. 7.Production-Customers-Water Losses in the Municipality of Larissa, Greece.

B. Cost of partial and total asphalt paving in the municipality of Larissa

In the municipality of Larissa and more specifically from

DEYAL, which is responsible for the water supply projects, $120 \mathrm{~km}$ of networks have been replaced from 2015 to 2019 and complete pavement reconstruction has been carried out on $600,000 \mathrm{~m}^{2}$.

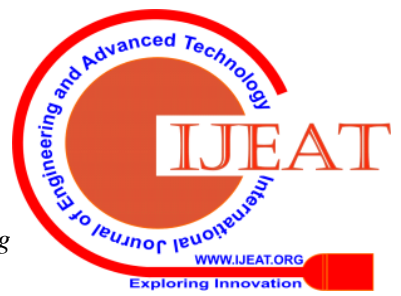


The cost of the works, according to data by DEYAL, amounts to 4.2 million $€$.

At this point arose the necessity of comparing the cost between partial pavement rehabilitation with local repairs (along with the old water network maintained) and full width pavement reconstruction (along with complete replacement of the water supply).

After investigating the records in the municipal business archive, it was found that the annual cost through the bidding projects for the restoration of pavement segments, due to various damages to water networks, amounts to 250,000 $€ /$ year.

Consequently, comparing the average cost of total pavement rehabilitation, with complete replacement of networks, to partial pavement restoration over a period of 20 years, clearly shows that full width operations are more economical than local treatments (Fig. 8).

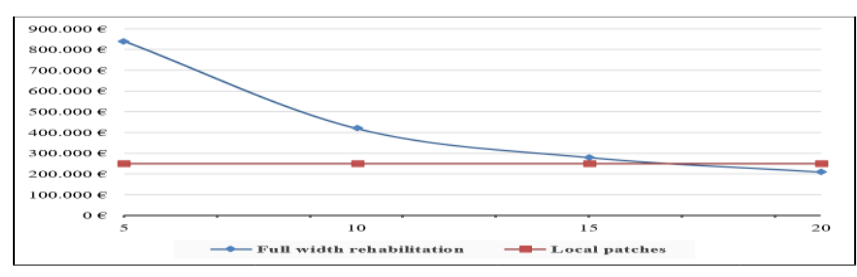

Fig. 8.Uniform cost values for pavement rehabilitation per year for different time-periods.

The period of 20 years was considered as a criterion for the rehabilitation of the districts of Larissa (Ag. Georgios, Hippocrates, Ampelokipi and Haravgi) through the assumption that the life cycle of a pavement replacement is about 15-20 years. After studying the diagram of Fig. 8 it is shown that the cost of full width operations (along with new water supply, PE-16atm pipes), with the costs of partial asphalting-patches (with old network, asbestos-iron pipes), are approximately the same in the duration of 17 years, while up to 20 years it is estimated that full width treatments are more economical than local works (patches) by 19\%, meaning about $800,000 €$ gain.

\section{Cost of flexible pavement per inhabitant for 20 years (200,000 inhabitants)}

The cost of total flexible paving over a period of 20 years per inhabitant, for a population of 200,000 (calculated on the basis of the number of hydrometers), is estimated at around $21 €$ per inhabitant, while the cost of local paving is $25 €$ per inhabitant. It is therefore understood that there are savings of $4 € /$ inhabitant in the first case (Fig. 9).

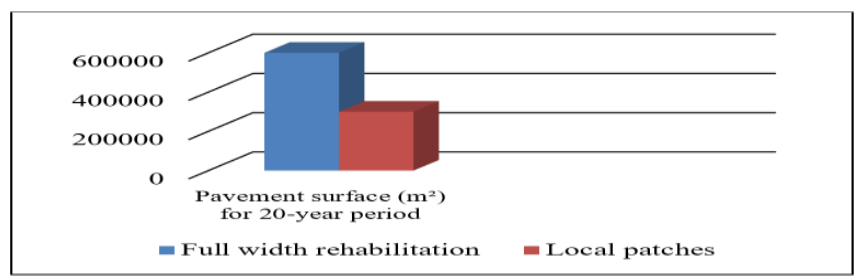

Fig. 9.Pavement rehabilitated surface for 20 -year period. D. Paving cost per hydrometer for 20 years

It is also important to convert the cost of paving per hydrometer, over 20 years, in cost per residence. So, for a total of 70,000 hydrometers in the municipality of Larissa, the cost of full width paving is $60 € /$ hydrometer, while for local treatments (patches), it is $71.5 €$ /hydrometer, respectively. The savings in the first case therefore amounts to $11.5 €$ /hydrometer, which in one-person households is substantially proportionate per inhabitant, thus increasing the savings in these cases.

\section{E. Total rehabilitated surface in 20 years}

A very important parameter is the rehabilitated surface between the two cases under study. In case of full width operation, for a 20-year time horizon, an area of 600,000 $\mathrm{m}^{2}$ is covered, while in the case of partial treatments (patches) for the same time period, it is revealed, through the investigation of the data that an area of $300,000 \mathrm{~m}^{2}$ is covered (Fig. 10).

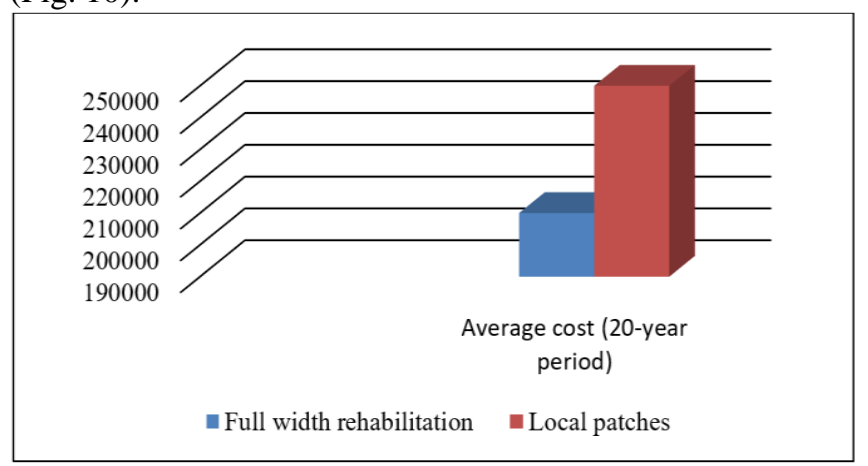

Fig. 10. Average cost of pavement rehabilitation.

\section{F. Rehabilitation cost per square meter for 20 years}

Another very important finding of the research is the paving cost per square meter over a 20 -year period. Total pavement replacement over a new water network costs 7 $€ / \mathrm{m}^{2}$, while local patches cost $16.5 € / \mathrm{m}^{2}$ (Fig.11). As can be seen, the cost difference is more than double between the two cases.

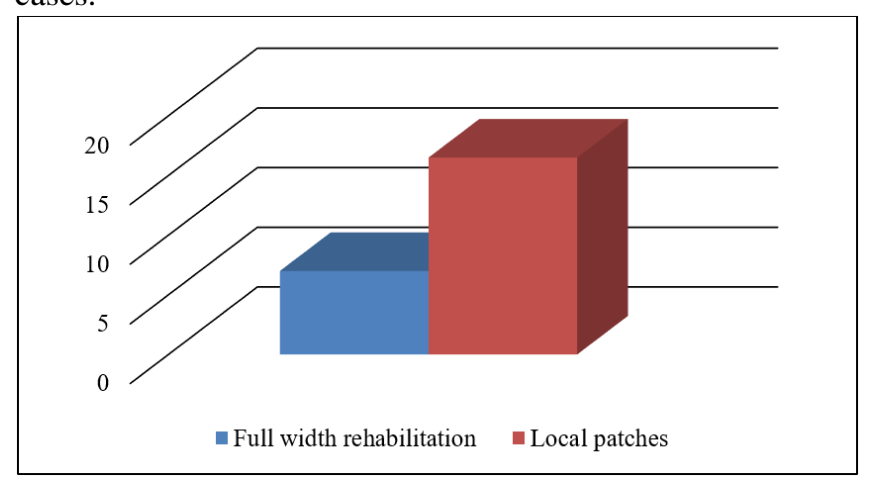

Fig. 11. Operations cost per square meter for 20-year period.

Table- I: Cost of pavement rehabilitation for 20 years

\begin{tabular}{|c|c|c|c|c|}
\hline $\begin{array}{c}\text { Rehabilitatio } \\
\text { n technics }\end{array}$ & $\begin{array}{c}\text { Pavement } \\
\text { rehabilita- } \\
\text { ted } \\
\text { surface. } \\
\left(\mathbf{m}^{2}\right)\end{array}$ & $\begin{array}{c}\text { Uniform } \\
\text { cost values } \\
\text { for } \\
\text { pavement } \\
\text { rehabilita- } \\
\text { tion. } \\
(€) \\
\end{array}$ & $\begin{array}{l}\text { Average } \\
\text { cost of } \\
\text { pavement } \\
\text { rehabilita- } \\
\text { tion. } \\
(€)\end{array}$ & $\begin{array}{c}\text { Operations } \\
\text { cost per } \\
\text { square } \\
\text { meter. } \\
(€)\end{array}$ \\
\hline $\begin{array}{c}\text { Full width } \\
\text { rehabilitation }\end{array}$ & 600.000 & 4.200 .000 & 210.000 & 7.0 \\
\hline Local patches & 300.000 & 5.000 .000 & 250.000 & 16.5 \\
\hline
\end{tabular}

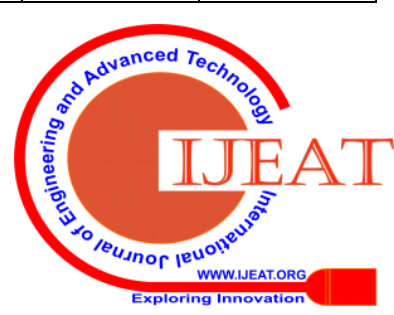




\section{CONCLUSIONS}

Concluding remarks refer to water losses in the municipality of Larissa, through network replacement, have dropped from $24 \%$ to $21 \%$ over the last 5 years (2015-2019). Water quality has improved through new PE networks in relation to the problematic asbestos-iron pipes which were adversely affected by corrosion. In addition, pipeline fractures have been practically eliminated after their full replacement with PE-16atm. Following the proposed method, better working conditions in the health sector for water supply workers due to the replacement of old pipes with those of modern polyethylene take place as well as better traction of vehicles in the case of total asphalting due to full road surface coverage, as opposed to scattered patches, while less noise from passing vehicles on full pavement exits, because the seams and potholes on the pavement are limited as opposed to paving the road in a limited width.

On the implementation example, $19 \%$ savings on resources and financial savings of $800,000 €$ over twenty years with full width pavement operations and new networks in relation to local treatments and maintenance of the old network in the municipality of Larissa are ascertained. Additionally, cheaper per capital total paving (with new water supply network) by $16 \%$ compared to local patches (with old water supply network) over a 20-year period, meaning $4 € /$ resident savings, as well as savings of $11.5 €$ per hydrometer with total network replacement for a 20-year period are calculated. The cost of full width rehabilitation with a new water supply network is $7 € / \mathrm{m}^{2}$ while localized treatments with the maintenance of the existing old network costs $16.5 € / \mathrm{m}^{2}$, which is $51.5 \%$ more economical for the first case, for a 20-year period. The square meters of full width rehabilitation are twice those of localized treatments, over a time period of 20 years, namely $600,000 \mathrm{~m}^{2}$ in the first case and $300,000 \mathrm{~m}^{2}$ in the second case.

In sum, conducting the proposed methodology, competent authorities, hold a useful tool in order to conclude to the optimal choice of water supply system rehabilitation operations with a cost-effective approach.

\section{REFERENCES}

1. A. K. Chapagain and A. Y. Hoekstra, "Virtual water flows between nations in relation to trade in livestock and livestock product", in Value of Water Research Report Series, No. 13, UNESCO-IHE Institute for Water Education, 2003, p. 28-59.

2. M.M. Mekonnen and A.Y. Hoekstra, "National water footprin accounts: the green, blue and grey water footprint of production and consumption", in Value of Water Research Report Series, No. 50, UNESCO-IHE Institute for Water Education, 2011, pp. 8-26.

3. World Wildlife Fund. Living Planet Report. WWF International, 2012, Gland, Switzerland.

4. S. Giljum, S. Lutter, M. Bruckner, S. Aparcana, "State-of-Play of National Consumption based Indicators, A review and evaluation of available methods and data to calculate footprint-type (consumption-based) indicators for materials, water, land and carbon", in Report for DG Environment of the European Commission. Sustainable Europe Research Institute (SERI), 2013.

5. A.Y. Hoekstra, A.K. Chapagain, M.M. Aldaya and M.M. Mekonnen, The Water Footprint Assessment Manual, Setting the Global Standard. London UK, Earthscan Ltd, 2011, pp. 141-155.

6. P.S. Kollias, Water supplies (surface - ground water, distribution networks, installations), Athens, Lychnos Pubications, ISBN-13 978-960-90597-0-1, 1998, pp. 163-171.

7. S.I. Kotsopoulos, Water supply, Athens, "ION" Publishing Group, ISBN 978-960-508-096-9, 2014, pp. 75-98.

8. N. Alamanis, Gr. Papageorgiou, P. Chantzopoulou, I. Chouliaras, "Investigation on the Influence of Permeability Coefficient k of the Soil

Mass on Construction Settlements. Cases of Infrastructure Settlements in Greece". WSEAS Transactions on Environment and Development, Vol. 15, 2019, Print ISSN: 1790-5079, E-ISSN: 2224-3496., pp. 95-105

9. Ch. Tsogas, Sewage and Wastewater Treatment Systems, Athens, "ION" Publishing Group, ISBN-13 978-960-405-801-3, pp. 327.

10. I.D. Kofitsas, Road Engineering Data, Athens, ION" Publishing Group, ISBN 978-960-411-185-5, 2001, pp. 314-365.

11. A.F. Nikolaidis, Flexible Pavements (dimensioning methods bituminous mixtures - friction layers), Thessaloniki, 1th ed., ISBN 978-960-91849-1-5, pp. 10-37.

12. S. Hou, Y. Liu, X. Zhao, M.R. Tillotson, W. Guo, and Y. Li, Blue and Green Water Footprint Assessment for China-A Multi-Region Input-Output Approach. Sustainability. 10, 2822. 2018. doi: 10.3390/su10082822.

13. D.A. Kampman. The water footprint of India. Master Thesis. University of Twente. The Netherlands, 2007.

14. A. Selvakumar, R.M. Clark and M. Sivaganesan. "Costs for Water Supply Distribution System Rehabilitation”. Journal of Water Resources Planning and Management. Vol. 8, Issue 4. 2002. doi 10.1061/(ASCE)0733-9496(2002)128:4(303).

\section{AUTHORS PROFILE}

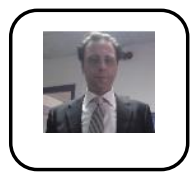

Dr. Grigorios Papageorgiou, Assistant Professor, University of Thessaly, Larissa, Greece.

$\mathrm{PhD}$ in Transport Infrastructure Management (University of Thessaly, Dept. of Civil Engineering), MSc in Environmental Design of Infrastructure Works (Hellenic Open University, School of Science and Technology), MSc in Environmental Design of Cities and Buildings (Hellenic Open University, School of Science and Technology), Member of Technical Chamber of Greece, Hellenic Association of Civil Engineers, Hellenic Institute of Transportation Engineers. He has published papers in international peer-reviewed journals and conferences at the field of Transport Infrastructure Management.

Research interests: smart roads, pavement management, environmental road design, highway infrastructure optimization.

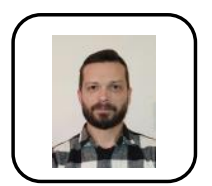

Christos Zografos. Civil Infrastructure Engineer, M.Sc Degree in Infrastructure Engineering, Dept. of Civil Engineering T.E., Technological Educational Institute of Thessaly. M.Sc. in Advanced Environmenta Management Technologies in Engineering Works (General Department of Larissa, University of Thessaly). Since 2007, he has been working as a supervising engineer at the Department of Technical Services, Municipal Water and Sewerage Company of Larissa (DEYAL), Larissa, Greece. He has overseen more than 20 hydraulic works of DEYAL, such as the construction of gravitational and pressing sewage pipes, replacements and extensions of water pipes, as well as many asphalt restoration projects in Larissa. He has many years of experience in the field of shoring in sewerage trenches. Since 2018, he has been a presenter of water supply and sewage pipeline program of DEYAL in primary and secondary schools of Larissa. Research interests: shoring in sewerage trenches, stability of slopes, hydrology and water resources management.

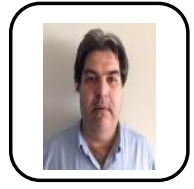

Dr. Nikolaos Alamanis, Assistant Professor $\mathrm{PhD}$ in Stability of Slopes (University of Thessaly, Dept. of Civil Engineering), D.E.A (Msc) Mecanique des Sols-Structures (Ecole Centrale Paris), MEng, BEng in Civil Engineering (integrated master from National Technical University of Athens, School of Civil Engineering). Member of Technical Chamber of Greece, Member of Hellenic Association of Civil Engineers, Member of American Society of Civil Engineering.

He has published papers in international peer-reviewed journals and conferences at the field of Geotechnical Engineering and Infrastructure Works.

Research interests: stability of slopes, spatial variability of soil properties, autocorrelation and cross correlation of soil strength parameters. 


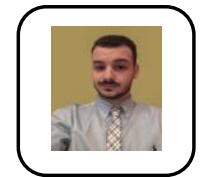

Nikolaos G. Xafoulis. Civil Infrastructure Engineer. Ph.D. Candidate at Laboratory of Eco-hydraulics \& Inland Water Management, University of Thessaly.

M.Sc. in Advanced Environmental Management Technologies in Engineering Works (Technological Educational Institute of Larissa).

Academic Scholar at P.S. of Civil Engineering T.E., University of Thessaly. He teaches "Computer Aided Applications on Hydraulic Works".

Research assistant in the laboratory of "Flooding Protection Hydraulic Works \& Water Resources Management Technology" at General Department of Larissa, University of Thessaly. He has published a number of papers in international peer-reviewed journals and conferences.

Research interests: river engineering, hydraulics of open flow channels, sediment transport in natural rivers, river flood protection works, hydrology and water resources management.

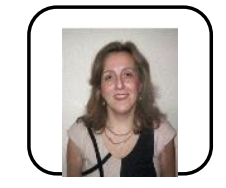

Dr. Evangelia Farsirotou. Professor at the Department of Ichthyology \& Aquatic Environment, School of Agricultural Sciences, laboratory of "Ecohydraulics \& Inland Water Management" at the University of Thessaly. Her scientific area is in "Hydrodynamic and Flood Prevention Works". She has a diploma in Civil Engineering, Ph.D. at the Aristotle University of Thessaloniki, Department of Civil Engineering in the Division of Hydraulics \& Environmental Engineering and Master of Science in Hydraulic Engineering. She is director of the Master of Science in "Advanced Environmental Management Technologies in Engineering Works" (General Department of Larissa, University of Thessaly). She teaches "Hydraulics", "Regulations of Rivers and Streams-Flood Prevention Works","Hydrodynamic Works - Dams", "Computer Aided Applications on Hydraulic Works", "Environmental Management of Natural Rivers" and "Flood Protection and Sustainable Development". She is active in research in hydraulics of open channels, river bed morphology and sediment transport, degradation, aggradation and scour simulation in alluvial channels and river flood protection works. She has published a number of papers in international peer-reviewed journals and conferences. Moreover, she has participated in the research projects titled: "Water Resources Management of coastal Agricultural Environments-Resilience of climate change impacts (Agroclima)" and "Investigation of the impact of the climate change on river deltas. Case study: the delta of river Pinios (Thessaly, Greece)". 